\title{
General Mental Ability and Specific Abilities: Their Relative Importance for Extrinsic
}

\section{Career Success}

\author{
Jonas W. B. Lang \\ Ghent University and University of Exeter
}

Harrison J. Kell

Educational Testing Service

\section{Accepted for publication, Journal of Applied Psychology}

Author Note

Jonas W. B. Lang, Department of Personnel Management, Work and Organizational Psychology, Ghent University, Ghent, Belgium, and Business School, University of Exeter, Exeter, UK; Harrison J. Kell, Educational Testing Service, Academic to Career Research Center, Research \& Development, Princeton, NJ.

We thank the American Institutes for Research for providing us with the data and for allowing us to analyze it.

Earlier versions of this paper have been presented at the $33^{\text {rd }}$ conference of the Society of Industrial and Organizational Psychology in Chicago in April 2018, the meeting of the European Network of Selection Researchers (ENESER) sponsored by the European Association of Work and Organizational Psychology (EAWOP) in Edinburgh in June 2018, and the Dutch-Flemish Meeting of Selection Researchers at Rotterdam in November 2018.

Correspondence concerning this article should be addressed to Jonas W. B. Lang, Department of Personnel Management, Work and Organizational Psychology, Ghent University, Henri Dunantlaan 2, 9000 Ghent, Belgium. Email: jonas.lang@ugent.be 


\begin{abstract}
Recent research on the role of general mental ability (GMA) and specific abilities in work-related outcomes has shown that the results differ depending on the theoretical and conceptual approach that researchers use. While earlier research has typically assumed that GMA causes the specific abilities and has thus used incremental validity analysis, more recent research has explored the implications of treating GMA and specific abilities as equals (differing only in breadth and not subordination) and has used relative importance analysis. In this paper, we extend this work to the prediction of extrinsic career success operationalized as pay, income, and the attainment of jobs with high prestige. Results, based on a large national sample, revealed that GMA and specific abilities measured in school were good predictors of job prestige measured after 11 years, pay measured after 11 years, and income 51 years later toward the end of the participants' work lives. With one exception, GMA was a dominant predictor in incremental validity analyses. However, in relative importance analyses, the majority of the explained variance was explained by specific abilities, and GMA was not more important than single specific abilities in relative importance analyses. Visuospatial, verbal, and mathematical abilities all had substantial variance shares and were also more important than GMA in some of the analyses. Implications for the interpretation of cognitive ability data and facilitating people's success in their careers are discussed.
\end{abstract}

Keywords: Cognitive abilities, intelligence, income, success, longitudinal 
General mental ability (GMA) is one of the most frequently used predictors in psychological science, historically and currently (Mackintosh, 2011), that captures ability across a broad set of cognitive tasks. Recently, researchers have extended inquiry into the applied value of GMA by systematically examining the degree to which it predicts extrinsic career success such as pay and occupational prestige (Strenze, 2015). Although literature concerning intelligence and career success includes a large-scale study (Judge, Klinger, \& Simon, 2010) and a meta-analysis (Ng, Eby, Sorensen, \& Feldman, 2005), it is less extensive than existing research linking cognitive ability to job performance (Schmidt \& Hunter, 1998), counterproductive behavior (Gonzalez-Mulé, Mount, \& Oh, 2014), or leadership (Judge, Colbert, \& Ilies, 2004).

A recurring and important theme in the literature concerning the prediction of workrelated outcome criteria is the status of GMA in comparison to specific abilities from a set of content-homogenous tests (e.g., mathematical, verbal; Ryan \& Ployhart, 2014; Schmitt, 2013). Over the past 30 years many studies have shown that specific abilities contribute little incremental validity to predicting some work criteria like job performance and performance in training once GMA is accounted for (i.e., it is entered in the first step of a hierarchical regression or simultaneously with GMA, see e.g., Brown, Le, \& Schmidt, 2006; Ree \& Carretta, 2002). However, recent research has shown that the value of specific abilities vis-à-vis GMA considerably depends on theoretical assumptions (Kell \& Lang, 2017; Lang \& Bliese, 2012; Lang, Kersting, Hülsheger, \& Lang, 2010; Stanhope \& Surface, 2014). Specifically, it has been argued that it is theoretically justifiable to enter GMA in hierarchical regressions prior to specific abilities only if GMA is treated as a cause of variance in those abilities. However, there are alternative contemporary models of cognitive abilities that fit the data equally well and do not specify a causal relationship between GMA and specific abilities (e.g., Gustafsson, 2002; Kovacs 
\& Conway, 2016; van der Maas et al., 2006). When the association between GMA, specific abilities, and work outcomes is examined in accordance with these latter models, it is inappropriate to conduct incremental validity analyses. Instead, the relative importance of GMA and specific abilities for predicting work criteria is of interest.

In this paper, we draw on earlier work on the role of cognitive abilities in career success and extend this work by systematically examining GMA and specific abilities as predictors of extrinsic career success (early-career pay, late-career income, and occupational prestige). In so doing, we draw on both cognitive ability theories that assume a causal relationship between GMA and specific abilities and theories that explicitly do not assume such a relationship. Our objective in examining these phenomena is twofold.

First, we seek to further clarify the consequences of different cognitive ability theories for conclusions regarding the role of GMA and specific abilities in important work-related outcome criteria. By examining career success we contribute understanding of what are the long-term influences of specific abilities, complementing prior work that focused on assessments of performance (Ryan \& Ployhart, 2014; Sackett \& Lievens, 2008; Schmitt, 2013). It is reasonable to assume that people who are (objectively) successful in their careers exhibit better job performance in the long-run than those who are less successful - but the few studies that have examined the association between job performance and career progression (Carmeli, Shalom, \& Weisberg, 2007; Van Scotter, Motowidlo, \& Cross, 2000) have found that the association is not strong. Consequently, examining the relationship between cognitive abilities and career success is not redundant with looking at the association between abilities and performance.

Our second objective is to uncover ability antecedents that can be identified relatively early in people's lives and that may drive successful careers. This second objective has 
potentially important consequences for detecting, developing, and selecting talent at an early stage, given that individuals' rank-ordering vis-à-vis their cognitive abilities tends to be relatively stable over time (Deary, Pattie, \& Starr, 2013). It also has important implications for assisting policymakers in developing educational environments and early interventions that are specifically targeted to enhance abilities implicated in success.

\section{Theoretical Background}

\section{Conceptualizing Careers}

We situate our investigation in several prevailing approaches to conceptualizing individuals' careers. We briefly review these perspectives below.

Objective career success. Objective (or extrinsic) career success is typically defined as accomplishments that individuals achieve through their work and that can objectively verified or observed by others ( $\mathrm{Ng}$ et al., 2005). The most common extrinsic career success criteria are pay, income, and the achievement of occupational status/prestige. While pay represents the economic compensation that individuals receive for their work and income individuals' overall financial success (Peters, 1992), occupational prestige or status captures the social standing or the way society overall views an occupation (Hauser \& Warren, 1997). Although these criteria are related, the correlation in most samples is typically only moderate (Judge, Higgins, Thoresen, \& Barrick, 1999; Weaver, 1977). The discrepancy between prestige and pay/income results from the fact that some high-prestige occupations in many societies are state servants that receive a fixed salary; individuals may forego the possibility of making extraordinary amounts of money and choose these jobs (e.g., judge) based on their high prestige and relative stability. Additionally, some other high-paying jobs require advanced degrees and/or extreme levels of technical skill that are relatively rare for the population at large to possess and, consequently, the 
general public remains largely unaware of many of these jobs (e.g., oil \& gas diver); an occupation cannot be prestigious if few people are aware that it exists. Finally, it is possible that individuals do not manage their financial assets well so that their job-related pay differs from income, particularly late in life.

Human capital perspective. There are multiple conceptualizations of how individuals go about succeeding in their careers. For this investigation we adopt the human capital view (Becker, 1964), which is generally oriented toward the perspective that individuals have competencies or attributes (e.g., abilities, knowledge, skills) and that individuals are rewarded throughout their careers to the extent that they mobilize these competencies in the service of organizational and/or societal success. Individuals who possess and better mobilize these internal resources are more likely to be rewarded in their organizations and across their careers - such as by being promoted more quickly, earning greater pay, and possessing jobs that hold higher societal prestige value.

Human capital attributes can be conceptualized in multiple ways (Melamed, 1996). First, they differ in their generality, with some attributes (e.g., cognitive skills, personality traits) being considered highly general - given they are applicable to a very wide variety of jobs - and some being considered highly specific (e.g., knowledge of an individual organization's policies and procedures), as they are applicable to only a small number of jobs. We treat general mental ability as a variety of general human capital but we also consider specific cognitive abilities to constitute a type of general human capital; specific abilities are not as widely applicable as general cognitive ability but many (e.g., quantitative, verbal, visuospatial skills) are relevant to a very wide variety of jobs (Hunt \& Madhyastha, 2012; Kyllonen, Carrasco, \& Kell, 2017).

Second, human capital attributes differ in their ease of malleability, with relatively easily 
modifiable attributes and attributes relatively difficult to modify (Baruch \& Bozionelos, 2010). Individuals' rank-ordering on cognitive abilities tends to be highly stable over even very long periods of time (Deary et al., 2013) and, accordingly, retain their predictive value for practical criteria over extended periods (Judge et al., 1999). Moreover, although these abilities can be modified through life experience, education, and intentional interventions (Protzko, Aronson, \& Blair, 2013; Ritchie \& Tucker-Drob, 2018), they are nonetheless difficult to alter and the effects of interventions tend to fade if they are not maintained (Protzko, 2015).

\section{The Status of GMA and Specific Abilities}

Table 1 provides an overview of major ideas about the status of general and specific abilities. Most relevant for the present study is that these conceptualizations make different assumptions about the causal priority of general and specific abilities. Two-factor theory and the higher-order model assume that GMA has a causal effect on specific abilities. In contrast, the nested-factors and the hierarchies of factor solutions models make no assumption about the causal relations among general and specific abilities. Finally, the bonds and the mutualism models put general and specific abilities on a continuum from specific to general and assume that the causal order is from specific elements (bonds or ecosystems) to general abilities - the opposite of the two-factor and higher-order theories. A conceptual problem of intelligence research is the fact that it is not easy to make a decision about which of the existing conceptualizations best captures the true underlying nature of the data; many of the models (e.g., bonds, mutualism) fit the data equally well (Bartholomew, Allerhand, \& Deary, 2013; van der Maas et al., 2006), with some (e.g., higher-order, nested-factors) capable of being statistically transformed into the other (Murray \& Johnson, 2013). While even strong proponents of GMA (e.g., Eysenck, 1997; Jensen, 1987) have stated that data from outside the realm of factor 
analysis will be the ultimate arbiter of the scientific status of the nature of cognitive abilities, neuroscientific (Deary, Penke, \& Johnson, 2010), historical (Flynn, 2007), and longitudinal data (McArdle, Hamagami, Meredith, \& Bradway, 2000) offer contradictory accounts of the primacy of general and specific abilities.

\section{Incremental Validity and Relative Importance}

A frequently used research strategy in the existing literature on general and specific abilities in outcome criteria is to use incremental validity analyses that enter GMA as the predictor in a first step (e.g., Brown et al., 2006; Ree \& Carretta, 2002). In the second step, the specific abilities are then added to examine the variance that these abilities explain after controlling for GMA. This research strategy is in line with the theoretical ideas of both twofactor theory and the higher-order model and is consistent with the recommendation that variables that are assumed to have causal priority are entered first in hierarchical regressions (Cohen, Cohen, West, \& Aiken, 2003). As a result of the assumption that GMA precedes the specific abilities, all variance that GMA shares with the specific abilities is attributed to GMA. Research using this research strategy has frequently found that specific abilities do not explain much additional variance beyond GMA. Incremental validity analyses are frequently insightful when the focus is on the pragmatic improvement of an existing prediction system (LeBreton, Hargis, Griepentrog, Oswald, \& Ployhart, 2007). However, a problem with cognitive ability research using incremental validity analyses is that incremental validity estimates are only meaningful when the assumption that GMA causes the shared variance between itself and specific abilities is actually correct. Considering the issues in testing this assumption in fundamental research, definitive conclusions as to the relationship between general and specific abilities are lacking. Applied researchers often still face the need to understand the role both 
types of ability play when predicting outcomes. Therefore, it may frequently be informative to study the role of GMA and specific abilities in relevant outcome criteria without making preliminary assumptions about their causal ordering, in addition to studying incremental validity. There are two approaches that allow researchers to do so.

The first approach is to estimate a nested factors model using structural equation modeling software and to then link the latent nested factors directly to the outcome criterion (Gustafsson \& Balke, 1993; Reeve, 2004). A limitation of this approach is that it requires that the research makes the assumption that GMA and the specific abilities are orthogonal in the model, thereby distributing shared variance between GMA and the specific abilities.

The second approach is to use regression techniques that do not require preliminary assumptions about the causal order of correlated predictors. Methodological research suggests that the most suitable technique for comparing the magnitude of the relationship between different predictors and outcome criteria is relative importance analysis (M. T. Braun, Converse, \& Oswald, 2019; Budescu, 1993; Johnson \& LeBreton, 2004; LeBreton et al., 2007; LeBreton, Ployhart, \& Ladd, 2004). Relative importance is typically defined as "the contribution a variable makes to the prediction of a criterion variable by itself and in combination with other predictor variables" (Tonidandel \& LeBreton, 2011; p. 2). Modern relative importance analysis techniques produce a rank order of correlated predictors and distribute the overall $R^{2}$ among the predictors. Relative importance statistics thus provide direct insights into the role that a particular predictor has in an outcome criterion without the assumption of a causal order. These characteristics are major advantages over other regression metrics like semipartial correlations, partial correlations, or beta weights that describe the effect of a predictor on an outcome variable after controlling for another predictor, and that do not provide a rank order or distribute the overall $R^{2}$. 


\section{Linking General Ability and Specific Abilities with Extrinsic Career Success}

Research on the role of specific abilities in career success has typically emphasized the role of GMA, and existing studies have consequently focused on GMA. These existing studies include a relatively small meta-analysis ( $\mathrm{Ng}$ et al., 2005) that found moderate effects of GMA on pay and job prestige, and a study with a large sample that found similar effects (Judge et al., 2010). In line with this earlier research, we hypothesized that GMA would predict extrinsic career success criteria (early-career pay, end-career income, and job prestige in this study).

\section{Hypothesis 1: GMA predicts extrinsic career success criteria.}

In extending earlier research on extrinsic career success, we studied the role of specific abilities in GMA using both an incremental validity perspective and a relative importance analysis approach. Analogous to research on job performance, we assumed that specific abilities would not have much incremental validity (Brown et al., 2006; Ree \& Carretta, 2002).

Hypothesis 2: In incremental validity analyses entering GMA first, GMA accounts for the majority of the explained variance in extrinsic career success criteria.

However, given that incremental validity analyses make the somewhat problematic assumption that GMA is the source of all shared variance between GMA and the specific abilities, we expected different findings in the context of relative importance analyses that do not make this assumption. We specifically expected that specific abilities would account for the majority of the explained variance in extrinsic career success criteria and that single specific abilities would be equally important in extrinsic career success criteria as GMA. These expectations were based on two theoretical rationales. First, we based these expectations on the conceptualizations in Table 1 (Bonds model, nested-factors/bi-factor model, mutualism model, and hierarchies of factor solutions conceptualization) that suggest that GMA is not the causal 
source of the positive manifold. When shared variance is not necessarily caused by GMA, it is reasonable to assume that specific abilities may emerge as relatively important predictors in realworld settings under the condition that the criterion requires these specific abilities. Second, we based our expectations on the importance of specific abilities on earlier theoretical and empirical work arguing that job-related outcomes like career success actually require specific abilities (Schneider \& Newman, 2015; Wai, Lubinski, \& Benbow, 2009). Our theoretical expectations were also in line with earlier research on other outcomes like job performance and training criteria suggesting that GMA is not always the single most important predictor in relative importance analyses (Kell \& Lang, 2017; Lang et al., 2010; Stanhope \& Surface, 2014). Hypothesis 3: In relative importance analyses including GMA and specific abilities, specific abilities account for the majority of the explained variance in extrinsic career success criteria.

Hypothesis 4: In relative importance analyses, single specific abilities are equally or even more important in extrinsic career success criteria than GMA.

One potential implication of studying the role of specific abilities in relevant outcome criteria is the fact that specific abilities provide more insight into why individuals obtain jobs with higher income and prestige (and, perhaps, why these jobs pay more and have higher prestige). Although more than three specific abilities exist (see e.g., the models in Table 1), we focus our hypotheses on visuospatial, verbal, and mathematical abilities, as three core content abilities (Guttman, 1954; Guttman \& Levy, 1991; Lubinski, 2000; Wilhelm, 2005). One idea in the literature is that visuospatial abilities are particularly relevant for success in jobs in science, engineering, technology, and mathematics (STEM; Kell, Lubinski, Benbow, \& Steiger, 2013; Lubinski, 2010; Wai et al., 2009) that are now and historically in demand and are on average 
high-paying (Koncz, 2016; Vilorio, 2014). These jobs require employees to work with spatial representations when they, for instance, read diagrams, interpret graphs, visualize molecules, comprehend cross-sections in biological images or geology plots, or imagine distances and sometimes very high velocities (Uttal \& Cohen, 2012). Visuospatial abilities are also important for complex math, which frequently requires an understanding of three-dimensional spatial representations. Visuospatial ability thus forms a valued resource that can generate economic progress (National Science Board, 2015).

Hypothesis 5: Visuospatial ability is a relatively important predictor of pay and income. In contrast to high pay and income that can frequently be achieved with technical or science skills, a common characteristic of jobs with high job prestige is that achieving success requires a lot of verbal communication and high levels of education. Examples include university professors in some disciplines, judges, or civil servants. Jobs that require less verbal skills frequently have comparatively lower job prestige (Gottfredson \& Brown, 1978; Smith \& Son, 2014). For instance, engineers have typically lower job prestige than judges, and technicians and electricians typically earn salaries comparable to teachers but have lower job prestige (e.g. p. 383; U.S. Bureau of the Census, 1976). An earlier meta-analytic study has already suggested that verbal abilities may be a primary driver behind the cognitive ability-job performance relationship by documenting high relative importance of verbal abilities in general job performance (Lang et al., 2010). This finding is also in line with the observation that some short general mental ability tests that are used successfully and frequently in practice are primarily measuring verbal abilities (e.g., Miller Analogies Test, Wonderlic Personnel Test).

Hypothesis 6: Verbal ability is a relatively important predictor of job prestige.

We finally also included specific hypotheses about mathematical ability. Mathematical 
ability features prominently in selection tests and mathematical abilities are also frequently required as entry level abilities in order to get into academic careers. For instance, economists typically need to pass difficult econometrics courses. Mathematical abilities, as might be expected, also play a critical role in obtaining and advancing in STEM occupations (Kell et al., 2013; Makel, Kell, Lubinski, Putallaz, \& Benbow, 2016; Wai et al., 2009).

Hypothesis 7: Mathematical ability is a relatively important predictor of extrinsic career success criteria.

\section{Method}

To conduct our investigation we used data from three time points of Project TALENT, a 1960 national longitudinal study from the United States including approximately 5\% of the high school students in grades 9 to 12 (Flanagan et al., 1961). The initial main data collection occurred in 1960. The original participants were followed up several times and the dataset is frequently used in I-O psychology research (e.g., Austin \& Hanisch, 1990; Sackett, Kuncel, Arneson, Cooper, \& Waters, 2009). In this study, we focused on extrinsic career success criteria from the 1971-1974 follow up ( $n=84,831$ for pay, and $n=15,810$ for job prestige), and the 2011-2012 reconnect study (data on income from $n=1,796$ participants) that has to our knowledge not been used in research projects on cognitive abilities so far.

Students' cognitive abilities were assessed by 17 tests in 1960. A parallel analysis of all cases with not more than one of the 17 test scores missing $(n=363,607)$ suggested the presence of five specific abilities because the first five eigenvalues $(6.14,1.04,0.69,0.29,0.11,0.02$, and $-0.02)$ were higher than simulated eigenvalues $(0.32,0.06,0.05,0.04,0.03,0.02$, and 0.02$) . \mathrm{A}$ principal axis factor analysis with oblimin rotation indicated that the five factors could be clearly interpreted as verbal ability, coding speed, visuospatial ability, mathematical ability, and short- 
term memory (see Table 2). We also conducted a one-factor factor analysis and found that the general factor explained 36 percent of variance (see Table 2). For subsequent analyses, we generated unit-weighted composite scores (Bobko, Roth, \& Buster, 2007) by first $z$-standardizing all variables and then taking the average for each composite.

We studied three extrinsic career success criteria. Early-career pay was measured using the participants' self-report in 1971-1974 when most participants had finished college and had a job and indicated what they made annually in an open question ("How much was your pay or other earnings (before deductions) on this job?"). As a measure job prestige, we used the available information on the classification of participants' job in 1971-1974 on the job categories in the Dictionary of Occupational Titles (U.S. Department of Labor., 1970). We then linked this information to available Siegel prestige scores for the participants' jobs published by Gottfredson and Brown (1978). Classification information from Project TALENT was available for 16,883 participants and linking to Prestige scores reduced the sample size to 15,810 because of missing prestige ratings for some jobs. Prestige scores have a theoretical range from 0 to 100 and are based on a series of surveys conducted in the 1960 s - and the rank-ordering of prestige ratings has been found to be highly stable over time (Hauser \& Warren, 1997; Smith \& Son, 2014). Finally, late-career income was measured in the reconnect study in 2011-2012 when the participants $(n=1,796)$ mostly had fully or partly retired so that their income also included income from savings and pensions and was affected by other life decisions. They answered the question "Thinking of all income source of your household, what was your total household income in 2010"? on an scale ranging from $1=$ less than $\$ 10,000,2=\$ 10,000$ to $\$ 49,999,3=$ $\$ 50,000$ to $\$ 99,999,4=\$ 100,000$ to $\$ 149,999,5=\$ 150,000$ or more.

\section{Analyses}


Inverse probability weighting. Because the study is based on a substantive population of high-school students, it was possible to correct for sample attrition. To perform these corrections, we relied on inverse probability weighting (IPW; Seaman \& White, 2013; Thoemmes \& Ong, 2016; Wooldridge, 2007). IPW includes three steps. The first step includes a logistic regression analysis with the study status at follow up (attrition yes/no) as the dependent variable and the variables of interest on which the two groups potentially differ as the independent variables (the 1960 ability predictors in our research). In the second step, propensity scores are calculated on the basis of the logistic regression analysis. In the final and third step, the inverse of the propensity scores (1/PS) is used as sampling weights in the main analysis thereby removing differences between the follow-up samples and the full sample with regard to their mean abilities in 1960. IPW only requires a model for the probability that an individual has complete data — a univariate outcome (Seaman \& White, 2013; Thoemmes \& Ong, 2016). In contrast, other approaches require more assumptions (e.g., multiple imputation needs a model for the joint distribution of the missing data — a multivariate outcome — given the observed data). In the present study, there was very limited missing data in the initial and follow-up data collections but attrition was substantial making the dataset well suited for IPW.

Attenuation corrections. We corrected all cognitive ability predictors for measurement error using the internal consistencies across the tests included in each ability measure and the Spearman attenuation correction formula, $\rho_{T_{x} T_{y}}=\frac{\rho_{x y}}{\sqrt{\rho_{x x} \rho_{y y \prime}}}$. In the special case of the correlations between the specific ability composites and the general ability composite, we relied on Zimmerman and Williams' (1977) extended attenuation correction formula $\rho_{T_{x} T_{y}}=$ $\frac{\rho_{x y}-\rho_{E_{x} E y} \sqrt{1-\rho_{x x}} \sqrt{1-\rho_{y y \prime}}}{\sqrt{\rho_{x x} / \rho_{y y}}}$ to adjust for the fact that the inclusion of tests in both the specific and the general ability composite results in correlated measurement error, $\rho_{E_{x} E_{y}} \cdot \rho_{E_{x} E_{y}}$ can be estimated 
using Nunnally and Bernstein's (1994, p. 173) composite correlation formula, $r_{w y}=\frac{\bar{R}_{w y}}{\sqrt{\bar{R}_{w}} \sqrt{\bar{R}_{y}}}$ when one assumes that measurement errors between independent tests are not correlated and identical measures are correlated with $1 .{ }^{1}$

The income and pay variables in the present study and the DOT job classification on which the prestige score was based were objective criteria. In line with earlier work, we therefore did not correct for measurement error (e.g., Kuncel, Hezlett, \& Ones, 2001).

Incremental validity and relative importance analyses. We ran analyses using the three core specific abilities for which we developed theoretical hypotheses and a GMA composite based on the tests included in these core specific abilities. In the incremental validity analyses, we first entered GMA and then each of the specific abilities and also all specific abilities in the second step. In the relative importance analyses, we used dominance weights because it is the most widely accepted modern approach to relative importance analysis (M. T. Braun et al., 2019; Grömping, 2015; LeBreton et al., 2004). We estimated bootstrap confidence intervals for all variance shares using the relaimpo package (Grömping, 2006) and the boot package in the R environment (R Core Team, 2018). In supplementary analyses, we also ran the same analyses with all tests included in Table 2 and all five specific abilities including the two for which we did not develop hypotheses (short-term memory and coding speed).

\section{Results}

Table 3 provides means, standard deviations, intercorrelations, and sample sizes for the study variables. As shown in Table 3, the ability composites were positively correlated with the three extrinsic career success criteria. The positive relationship of GMA with all three criteria supports Hypothesis 1.

Table 4 and Figures 1A, 2A, and 3A include results from the incremental validity 
analyses to study our Hypothesis 2 that specific abilities would not explain much additional variance in extrinsic career success when GMA is entered first in incremental validity analyses (making the assumption that GMA has a causal effects on the specific abilities). The results confirmed these ideas for job prestige in 1971-1974 and income in 2011-2012. For pay in 19711974 (see Table 4 and Figure 1A), visuospatial ability explained a considerable amount of incremental variance, and verbal ability also showed sizeable incremental validity albeit with a negative $\beta$ weight. These findings were somewhat unexpected on the basis of the earlier literature on job performance. A potential explanation is that jobs that require visuospatial abilities like science and technical jobs (e.g., engineer) may pay good wages also early in the participants' careers. In contrast, high prestige jobs (e.g., lawyer) frequently only lead to a high wage after a long education and career. Overall, our findings partly support Hypothesis 2.

We next examined the results for the relative importance analyses shown in Table 5 and Figure 1B, 2B, and 3B to address our Hypotheses 3 to 7 . As indicated in Table 4 and the figures, the results show that GMA was not more important than the specific abilities and only explained a comparatively small amount of the overall explained variance. The majority of the explained variance was explained by specific abilities, and these results thus support our Hypotheses 3 . The rank orders and confidence intervals also indicate that GMA was not more important than all single specific abilities in any of the relative importance analyses. These results support our Hypothesis 4 suggesting that single specific abilities are equally important as GMA.

We also examined our hypotheses about which specific abilities would be particularly good predictors of the extrinsic job criteria in Project TALENT. As shown in Figure 1B, visuospatial ability had a strong relative weight for pay in 1971-1974 and especially the relative weight for visuospatial ability clearly exceeded the weight for GMA. In contrast, visuospatial 
abilities were important for income in 2011-2012 (see Figures 3B) but not more important than GMA. Overall, these findings partially support Hypothesis 5 (visuospatial ability is important for pay and income). We next examined the role of verbal ability in job prestige. The results revealed that verbal ability was indeed an important predictor of job prestige and did not substantially differ from GMA in importance confirming Hypothesis 6. Finally, we examined the relative importance of mathematical ability. As shown in Figures 1B, 2B, and 3B, mathematical ability was more or equally important as GMA in all analyses and consistently one of the three most important abilities, confirming Hypothesis 7.

We finally ran the supplementary analyses with all five specific abilities including the two specific abilities for which we did not develop hypotheses. As shown in the supplementary Tables S1, S2, and S3, the conclusions regarding our hypotheses did not fundamentally change. However, the variance shares for GMA relative to the most important specific ability in the relative importance analyses became somewhat smaller $(1.7 \%$ vs $5.3 \%, 6.0 \%$ vs. $6.3 \%$, and $1.9 \%$ vs. 4.6\% for pay in 1971-1974, job prestige in 1971-1974, and income in 2011-2012, respectively) and there were some changes in the exact rank-order of the abilities.

\section{Discussion}

We used data from a large longitudinal study that tracked participants from high school until retirement age and examined the role of different abilities in their extrinsic career success (pay, income and job prestige). This study extends previous research examining the relative importance of GMA and content-aligned specific abilities for predicting job performance (Kell \& Lang, 2017; Lang \& Bliese, 2012; Lang et al., 2010)—now increasingly recognized in the personnel selection literature (e.g., Hanges, Scherbaum, Goldstein, Ryan, \& Yusko, 2012; Ryan \& Ployhart, 2014; Schmitt, 2013) — to another research domain. While findings on the role of 
specific abilities in job performance have potential implications for selection decisions, findings on extrinsic career success are more broadly relevant to individuals' lifelong experiences.

Our results revealed that GMA typically accounted for nearly all of the explained variance in the criterion in incremental validity analyses with specific abilities adding a trivial additional amount of explained variance (However, the results for pay in 1971-1974 are an exception, see Figure 1). For these same criteria, however, when relative importance analyses were conducted, the majority of the explained variance was explained by specific abilities and GMA was ranked either as equal or below single specific abilities. The findings for the specific abilities also provided insights into unique characteristics of the extrinsic career success criteria (see Figures 1, 2, and 3).

From a theoretical perspective, this study underscores the important role that different theoretical outlooks and fundamental research about intelligence can play when conducting investigations of even highly practical topics, along with the need to select analytic strategies capable of representing those outlooks methodologically. The field of intelligence is currently in the midst of a vigorous, exciting debate about the nature and structure of the construct(s) that underlie performance on cognitive tests as evidenced by the emergence and re-emergence of theories that do not assume that the $g$ factor is causal (see Table 1). Many leading cognitive ability researchers are thus open-minded about the status and interpretation of GMA. With this open-mindedness have come explicit calls for more research into the value of specific cognitive abilities (Coyle, 2014) and the view that intelligence includes all cognitive abilities instead of seeing intelligence as a construct that is synonymous with GMA (Carroll, 1997) is increasingly recognized (Schneider \& Newman, 2015; Stankov, 2017). Open-mindedness about the status of GMA, along with the results of this study and others (e.g., Lang \& Bliese, 2012; Lang et al., 
2010) that do not show it to be of overwhelming importance, should not be taken as evidence that GMA is unimportant: Findings consistently demonstrate substantial correlations with workrelevant outcomes and even if the rank-order of a predictor in a relative importance analysis is not \#1 it can still account for a substantial amount of criterion variance.

This study has several strengths and limitations related to the nature of the Project TALENT data. A strength of the Project TALENT study is the representative nature of the initial sample and the fact that the data extends across essentially the entire professional life of the participants (a 50 year timespan). However, a limitation of the Project TALENT is the fact that the extrinsic career success data were gathered near the beginning and end of participants' careers only. Accordingly, we could not investigate the relationship between intelligence and success during midlife, roughly corresponding to the maintenance (Super, 1957, 1980) or midcareer stage (Melamed, 1996; Lam, Ng, \& Feldman, 2012). Future research would benefit from examining the relative importance of abilities at more stages of individuals' careers.

Another limitation is that our investigation was restricted to early-career pay, late-career income, and job prestige. These three criterion measures are widely-used measures of career success (e.g., Cox \& Harquail, 1991; Judge et al., 1999; Lam, Ng, \& Feldman, 2012; Melamed, 1996; Slocum \& Cron, 1985; Whitely, Dougherty, \& Dreher, 1991). However, these measures capture somewhat distinct aspects of success because high-paying jobs do not always have high prestige and because income captures elements of success beyond simply getting a high-paying job. In future research, it likely makes sense to include additional measures of career success. For instance, measuring salary progression and number of promotions could be of interest in early career stages (Cox \& Harquail, 1991), and more detailed questions about the investment strategies of late-career/retired participants may be helpful (e.g., $401 \mathrm{Ks}$, investments, savings). 
Finally, a limitation of this and other longitudinal studies over very long periods of time is their generalizability across time; the findings of our study may be different had Project TALENT started later. Most notably, we found that visuospatial abilities were especially important for pay early in participants' careers but we did not find a similar effect for pay in retirement. These finding may not hold in future research because the nature of work and skill requirements have changed with the decline of many traditional manufacturing jobs, an increasingly aging workforce, and a broad need for older workers to acquire new, complex skills (Carnevale, Smith, \& Strohl, 2013; Charles, Hurst, \& Schwartz, 2013; Edgell, 2012).

Practically, this investigation's results provide insight into how developmental experiences (e.g., explicit training interventions, K-12 education) could potentially be designed and altered to facilitate people's success in their careers. Attempts to increase cognitive skills date back over a century (e.g., Binet, 1909; Thorndike \& Woodworth, 1901), with the majority of research finding that it is relatively rare (although not impossible; cf. Barnett \& Ceci, 2002; Karbach \& Kray, 2009) for training to transfer to another domain or broad range of other tasks (De Simoni \& von Bastian, 2018; Detterman, 1993). Evidence for near-transfer is much more commonly found (e.g., Melby-lervåg \& Hulme, 2013), however, suggesting that it may be more feasible to train specific cognitive abilities than GMA. Indeed, a recent 60-year longitudinal study showed that education tends to exert positive effects on specific cognitive abilities even while not influencing GMA (Ritchie, Bates, \& Deary, 2015). If future research uncovers good evidence that these relationships are of a causal nature, the prospect of enhancing intelligence in order to facilitate workforce success may be brighter when the goal is to train specific cognitive abilities, rather than GMA. 


\section{References}

Austin, J. T., \& Hanisch, K. A. (1990). Occupational attainment as a function of Abilities and interests: A longitudinal analysis using Project TALENT data. Journal of Applied Psychology, 75, 77-86. https://doi.org/10.1037/0021-9010.75.1.77

Barnett, S. M., \& Ceci, S. J. (2002). When and where do we apply what we learn? A taxonomy for far transfer. Psychological Bulletin, 128, 612-637. https://doi.org/10.1037/00332909.128.4.612

Bartholomew, D. J., Allerhand, M., \& Deary, I. J. (2013). Measuring mental capacity: Thomson's Bonds model and Spearman's g-model compared. Intelligence, 41, 222-233. https://doi.org/10.1016/j.intell.2013.03.007

Bartholomew, D. J., Deary, I. J., \& Lawn, M. (2009). A new lease of life for Thomson's Bonds Model of Intelligence. Psychological Review, 116, 567-579. https://doi.org/10.1037/a0016262

Baruch, Y., \& Bozionelos, N. (2010). Career issues. In S. Zedeck (Ed.), APA handbook of industrial and organizational psychology, volume 2: Selecting and developing members of the organization (pp. 67-113). Washington, DC: American Psychological Association.

Becker, G. S. (1964). Human capital: A theoretical and empirical analysis, with special reference to education. Washington, DC: National Bureau of Economic Research.

Binet, A. (1909). Modern ideas about children (translated by S. Heisler and published in 1973). Menlo Park, CA: Suzanne Heisler.

Bobko, P., Roth, P. L., \& Buster, M. A. (2007). The usefulness of unit weights in creating composite scores: A literature review, application to content, and meta-analysis. Organizational Research Methods, 689-709. https://doi.org/10.1177/1094428106/294734 
Braun, M. T., Converse, P. D., \& Oswald, F. L. (2019). The accuracy of dominance analysis as a metric to assess relative importance: The joint impact of sampling error variance and measurement unreliability. Journal of Applied Psychology, 104, 593-602. https://doi.org/10.1037/ap10000361

Brown, K. G., Le, H., \& Schmidt, F. L. (2006). Specific aptitude theory revisited: Is there incremental validity for training performance? International Journal of Selection and Assessment, 14, 87-100. https://doi.org/10.1111/j.1468-2389.2006.00336.x

Budescu, D. V. (1993). Dominance analysis: A new approach to the problem of relative importance of predictors in multiple regression. Psychological Bulletin, 114, 542-551. https://doi.org/10.1037/0033-2909.114.3.542

Carmeli, A., Shalom, R., \& Weisberg, J. (2007). Considerations in organizational career advancement: What really matters. Personnel Review, 36, 190-205. https://doi.org/10.1108/00483480710726109

Carnevale, A. P., Smith, N., \& Strohl, J. (2013). Recovery: Job growth and education requirements through 2020. Washington, DC: Georgetown University. Retrieved from https://cew.georgetown.edu/cew-reports/recovery-job-growth-and-education-requirementsthrough-2020/

Carroll, J. B. (1997). Psychometrics, intelligence, and public perception. Intelligence, 24, 25-52. Charles, K. K., Hurst, E., \& Schwartz, M. (2013). The transformation of manufacturing and the decline in U.S. employment (Working paper 24468). Cambridge, MA: National Bureau of Economic Research. https://doi.org/10.3386/w24468

Cohen, J., Cohen, P., West, S. G., \& Aiken, L. S. (2003). Applied multiple regression/correlation analysis for the behavioral sciences (3rd ed.). Hillsdale, NJ: Erlbaum. 
Cox, T. H., \& Harquail, C. V. (1991). Career paths and career success in the early career stages of male and female MBAs. Journal of Vocational Behavior, 39, 54-75. https://doi.org/10.1016/0001-8791(91)90004-6

Coyle, T. (2014). Predictive validity of non-g residuals of tests: More than g. Journal of Intelligence, 2, 21-25. https://doi.org/10.3390/jintelligence2010021

De Simoni, C., \& von Bastian, C. C. (2018). Working memory updating and binding training: Bayesian evidence supporting the absence of transfer. Journal of Experimental Psychology: General, 147, 829-858. https://doi.org/10.1037/xge0000453

Deary, I. J., Pattie, A., \& Starr, J. M. (2013). The stability of intelligence from age 11 to age 90 years. Psychological Science, 24, 2361-2368. https://doi.org/10.1177/0956797613486487

Detterman, D. K. (1993). The case for the prosecution: Transfer as an epiphenomenon. In D. K. Detterman \& R. J. Sternberg (Eds.), Transfer on trial: Intelligence, cognition, and instruction (pp. 1-24). Westport, CT: Ablex Publishing.

Edgell, S. (2012). The sociology of work: Continuity and change in paid and unpaid work (2nd ed.). London, UK: Sage.

Eysenck, H. J. (1997). Personality and experimental psychology: The unification of psychology and the possibility of a paradigm. Journal of Personality and Social Psychology, 73, 12241237. https://doi.org/10.1037/0022-3514.73.6.1224

Flanagan, J. C., Dailey, J. T., Shaycoft, M. F., Gorham, W. A., Orr, D. B., Goldberg, I., \& Clinton A. Neyman, J. (1961). Project TALENT. Washington, DC: Project Talent Office. Flynn, J. R. (2007). What is intelligence? Cambridge, UK: Cambridge University Press. Goldberg, L. R. (2006). Doing it all Bass-Ackwards: The development of hierarchical factor structures from the top down. Journal of Research in Personality, 40, 347-358. 
https://doi.org/10.1016/j.jrp.2006.01.001

Gonzalez-Mulé, E., Mount, M. K., \& Oh, I.-S. (2014). A meta-analysis of the relationship between general mental ability and nontask performance. Journal of Applied Psychology, 99(6), 1222-1243. https://doi.org/10.1037/a0037547

Gottfredson, L. S., \& Brown, V. C. (1978). Holland codes for the 1960 and 1970 census detailed occupational titles (MS No. 1660). Journal of Supplement Abstract Service Catalog of Selected Documents in Psychology, 8, 22.

Grömping, U. (2006). Relative importance for linear regression in R: The package relaimpo. Journal of Statistical Software, 17(1). https://doi.org/10.18637/jss.v017.i01

Grömping, U. (2015). Variable importance in regression models. Wiley Interdisciplinary Reviews: Computational Statistics, 7, 137-152. https://doi.org/10.1002/wics.1346

Gustafsson, J.-E. (2002). Measurement from a hierarchical point of view. In H. L. Braun, D. G. Jackson, \& D. E. Wiley (Eds.), The role of constructs in psychological and educational measurement (pp. 73-95). Mahwah, NJ: Erlbaum.

Gustafsson, J.-E., \& Balke, G. (1993). General and specific abilities as predictors of reading achievement. Multivariate Behavioral Research, 28, 407-434. https://doi.org/10.1207/s15327906mbr2804

Guttman, L. (1954). A new approach to factor analysis: The radex. In P. Lazarfeld (Ed.), Mathematical thinking in the social sciences (pp. 258-348). New York, NY: Free Press.

Guttman, L., \& Levy, S. (1991). Two structural laws for intelligence tests. Intelligence, 15, 79_ 103. https://doi.org/10.1016/0160-2896(91)90023-7

Hanges, P. J., Scherbaum, C. A., Goldstein, H. W., Ryan, R., \& Yusko, K. P. (2012). I-O psychology and intelligence: A starting point established. Industrial and Organizational 
Psychology, 5, 189-195. https://doi.org/10.1111/j.1754-9434.2012.01430.x

Hauser, R. M., \& Warren, J. R. (1997). Socioeconomic indexes for occupations: A review, update, and critique. Sociological Methodology, 27, 177-298. https://doi.org/10.1111/14679531.271028

Holzinger, K. J., \& Swineford, F. (1937). The Bi-factor method. Psychometrika, 2, 41-54. https://doi.org/10.1007/BF02287965

Humphreys, L. G. (1981). The primary mental ability. In M. P. Friedman, J. P. Das, \& N. O’Connor (Eds.), Intelligence and learning (pp. 87-102). New York, NY: Plenum. Hunt, E., \& Madhyastha, T. M. (2012). Cognitive demands of the workplace. Journal of Neuroscience, Psychology, and Economics, 5, 18-37. https://doi.org/10.1037/a0026177

Jensen, A. R. (1987). The g beyond factor analysis. In R. R. Ronning, J. A. Glover, J. C. Conoley, \& J. C. Witt (Eds.), The influence of cognitive psychology in testing (pp. 87-142). Hillsdale, NJ: Erlbaum.

Johnson, J. W., \& LeBreton, J. M. (2004). History and use of relative importance indices in organizational research. Organizational Research Methods, 7, 238-257. https://doi.org/10.1177/1094428104266510

Judge, T. A., Colbert, A. E., \& Ilies, R. (2004). Intelligence and leadership: A quantitative review and test of theoretical propositions. Journal of Applied Psychology, 89, 542-552. https://doi.org/10.1037/0021-9010.89.3.542

Judge, T. A., Higgins, C. A., Thoresen, C. J., \& Barrick, M. R. (1999). The Big Five personality traits, general mental ability, and career success across the life span. Personnel Psychology, 52, 621-652. https://doi.org/10.1111/j.1744-6570.1999.tb00174.x

Judge, T. A., Klinger, R. L., \& Simon, L. S. (2010). Time is on my side: Time, general mental 
ability, human capital, and extrinsic career success. Journal of Applied Psychology, 95, 92107. https://doi.org/10.1037/a0017594

Karbach, J., \& Kray, J. (2009). How useful is executive control training? Age differences in near and far transfer of task-switching training. Developmental Science, 12, 978-990. https://doi.org/10.1111/j.1467-7687.2009.00846.x

Kell, H. J., \& Lang, J. W. B. (2017). Specific Abilities in the Workplace: More Important Than g? Journal of Intelligence, 5(2), 13. https://doi.org/10.3390/jintelligence5020013

Kell, H. J., Lubinski, D., Benbow, C. P., \& Steiger, J. H. (2013). Creativity and technical innovation: Spatial ability’s unique role. Psychological Science, 24, 1831-1836. https://doi.org/10.1177/0956797613478615

Koncz, A. (2016). Salary trends through salary survey: A historical perspective on starting salaries for new college graduates. NACE Journal, 1, 18-30. Retrieved from https://www.naceweb.org/job-market/compensation/salary-trends-through-salary-survey-ahistorical-perspective-on-starting-salaries-for-new-college-graduates/

Kovacs, K., \& Conway, A. R. A. (2016). Process overlap theory: A unified account of the general factor of intelligence. Psychological Inquiry, 27, 151-177.

https://doi.org/10.1080/1047840X.2016.1153946

Kuncel, N. R., Hezlett, S. A., \& Ones, D. S. (2001). A comprehensive meta-analysis of the predictive validity of the Graduate Record Examinations: Implications for graduate student selection and performance. Psychological Bulletin, 127, 162-181. https://doi.org/10.1037/0033-2909.127.1.162

Kyllonen, P., Carrasco, C. A., \& Kell, H. J. (2017). Fluid ability (Gf) and complex problem solving (CPS). Journal of Intelligence, 5, 28. https://doi.org/10.3390/jintelligence5030028 
Lam, S. S. K., Ng, T. W. H., \& Feldman, D. C. (2012). The relationship between external job mobility and salary attainment across career stages. Journal of Vocational Behavior, 80, 129-136. https://doi.org/10.1016/j.jvb.2011.05.002

Lang, J. W. B., \& Bliese, P. D. (2012). I-O psychology and progressive research programs on intelligence. Industrial and Organizational Psychology, 5, 161-166. https://doi.org/10.1111/j.1754-9434.2012.01423.x

Lang, J. W. B., Kersting, M., \& Beauducel, A. (2016). Hierarchies of factor solutions in the intelligence domain: Applying methodology from personality psychology to gain insights into the nature of intelligence. Learning and Individual Differences, 47, 37-50. https://doi.org/10.1016/j.lindif.2015.12.003

Lang, J. W. B., Kersting, M., Hülsheger, U. R., \& Lang, J. (2010). General mental ability, narrower cognitive abilities, and job performance: The perspective of the nested-factor model of cognitive abilities. Personnel Psychology, 63, 595-640.

LeBreton, J. M., Hargis, M. B., Griepentrog, B., Oswald, F. L., \& Ployhart, R. E. (2007). A multidimensional approach for evaluating variables in organizational research and practice. Personnel Psychology, 60, 475-498. https://doi.org/10.1111/j.1744-6570.2007.00080.x

LeBreton, J. M., Ployhart, R. E., \& Ladd, R. T. (2004). A Monte Carlo comparison of relative importance methodologies. Organizational Research Methods, 7, 258-282. https://doi.org/10.1177/1094428104266017

Lubinski, D. (2000). Scientific and social significance of assessing individual differences: “Sinking shafts at a few critical points." Annual Review of Psychology, 51, 405-444. https://doi.org/10.1146/annurev.psych.51.1.405

Lubinski, D. (2010). Spatial ability and STEM: A sleeping giant for talent identification and 
development. Personality and Individual Differences, 49, 344-351.

https://doi.org/10.1016/j.paid.2010.03.022

Mackintosh, N. (2011). IQ and human intelligence (2nd ed.). Oxford, UK: Oxford University Press.

Makel, M. C., Kell, H. J., Lubinski, D., Putallaz, M., \& Benbow, C. P. (2016). When lightning strikes twice: Profoundly gifted, profoundly accomplished. Psychological Science, 27, 1004-1018. https://doi.org/10.1177/0956797616644735

McArdle, J. J., Hamagami, F., Meredith, W., \& Bradway, K. P. (2000). Modeling the dynamic hypotheses of Gf-Gc theory using longitudinal life-span data. Learning and Individual Differences, 12, 53-79. https://doi.org/10.1016/S1041-6080(00)00036-4

Melamed, T. (1996). Career success: An assessment of a gender-specific model. Journal of Occupational and Organizational Psychology, 69, 217-242. https://doi.org/10.1111/j.20448325.1996.tb00612.x

Melby-lervåg, M., \& Hulme, C. (2013). Is Working Memory Training Effective ? A MetaAnalytic Review, 49(2), 270-291. https://doi.org/10.1037/a0028228

Murray, A. L., \& Johnson, W. (2013). The limitations of model fit in comparing the bi-factor versus higher-order models of human cognitive ability structure. Intelligence, 41, 407-422. https://doi.org/10.1016/j.intell.2013.06.004

National Science Board. (2015). Revisiting the STEM workforce: A companion to science and engineering indicators 2014. Arlington, VA: National Science Foundation.

Ng, T. W. H., Eby, L. T., Sorensen, K. L., \& Feldman, D. C. (2005). Predictors of objective and subjective career success: A meta-analysis. Personnel Psychology, 58, 367-408. https://doi.org/10.1111/j.1744-6570.2005.00515.x 
Peters, H. E. (1992). Patterns of intergenerational mobility in income and earnings. The Review of Economics and Statistics, 74, 456. https://doi.org/10.2307/2109490

Protzko, J. (2015). The environment in raising early intelligence: A meta-analysis of the fadeout effect. Intelligence, 53, 202-210. https://doi.org/10.1016/j.intell.2015.10.006

Protzko, J., Aronson, J., \& Blair, C. (2013). How to make a young child smarter: Evidence from the database of raising intelligence. Psychological Science, 8, 25-40. https://doi.org/10.1177/1745691612462585

R Core Team. (2018). R: A Language and Environment for Statistical Computing [Version 3.5]. Vienna, Austria: R Foundation for Statistical Computing. Retrieved from http://www.rproject.org/

Ree, M. J., \& Carretta, T. R. (2002). g2K. Human Performance, 15, 3-23. https://doi.org/10.1207/S15327043HUP1501\&02_02

Reeve, C. L. (2004). Differential ability antecedents of general and specific dimensions of declarative knowledge: More than g. Intelligence, 32, 621-652. https://doi.org/10.1016/j.intell.2004.07.006

Ritchie, S. J., Bates, T. C., \& Deary, I. J. (2015). Is education associated with improvements in general cognitive ability, or in specific skills? Developmental Psychology, 51, 573-582. https://doi.org/10.1037/a0038981

Ritchie, S. J., \& Tucker-Drob, E. M. (2018). How much does education improve intelligence? A meta-analysis. Psychological Science, 29, 1358-1369. https://doi.org/10.1177/0956797618774253

Ryan, A. M., \& Ployhart, R. E. (2014). A century of selection. Annual Review of Psychology, 65, 693-717. https://doi.org/10.1146/annurev-psych-010213-115134 
Sackett, P. R., Kuncel, N. R., Arneson, J. J., Cooper, S. R., \& Waters, S. D. (2009). Does socioeconomic status explain the relationship between admissions tests and post-secondary academic performance? Psychological Bulletin, 135, 1-22. https://doi.org/10.1037/a0013978

Sackett, P. R., \& Lievens, F. (2008). Personnel selection. Annual Review of Psychology, 59, 419450. https://doi.org/10.1146/annurev.psych.59.103006.093716

Schmidt, F. L., \& Hunter, J. E. (1998). The validity and utility of selection methods in personnel psychology: Practical and theoretical implications of 85 years of research findings. Psychological Bulletin, 124, 262-274. https://doi.org/10.1037/0033-2909.124.2.262

Schmitt, N. (2013). Personality and cognitive ability as predictors of effective performance at work. Annual Review of Organizational Psychology and Organizational Behavior, 1, 131213170931007. https://doi.org/10.1146/annurev-orgpsych-031413-091255

Schneider, W. J., \& Newman, D. A. (2015). Intelligence is multidimensional: Theoretical review and implications of specific cognitive abilities. Human Resource Management Review, 25, 12-27. https://doi.org/10.1016/j.hrmr.2014.09.004

Seaman, S. R., \& White, I. R. (2013). Review of inverse probability weighting for dealing with missing data. Statistical Methods in Medical Research, 22, 278-295. https://doi.org/10.1177/0962280210395740

Slocum, J. W., \& Cron, W. L. (1985). Job attitudes and performance during three career stages. Journal of Vocational Behavior, 26(2), 126-145. https://doi.org/10.1016/00018791(85)90013-2

Smith, T. W., \& Son, J. (2014). Measuring Occupational Prestige on the 2012 General Social Survey (GSS Methodological Report No. 122). Chicago, IL: NORC at the University of 


\section{Chicago.}

Spearman, C. (1904). “General intelligence," objectively determined and measured. American Journal of Psychology, 15, 201-292.

Spearman, C. (1939). Thurstone's work re-worked. Journal of Educational Psychology, 30, 116.

Stanhope, D. S., \& Surface, E. A. (2014). Examining the incremental validity and relative importance of specific cognitive abilities in a training context. Journal of Personnel Psychology, 13, 146-156. https://doi.org/10.1027/1866-5888/a000116

Stankov, L. (2017). Overemphasized “g .” Journal of Intelligence, 5, 1-10. https://doi.org/10.3390/jintelligence5040033

Strenze, T. (2015). Intelligence and success. In S. Goldstein, D. Princiotta, \& J. A. Naglieri (Eds.), Handbook of intelligence: Evolutionary theory, historical perspective, and current concepts (pp. 405-413). https://doi.org/10.1007/978-1-4939-1562-0

Thoemmes, F., \& Ong, A. D. (2016). A primer on inverse probability of treatment weighting and marginal structural models. Emerging Adulthood, 4, 40-59. https://doi.org/10.1177/2167696815621645

Thomson, G. H. (1916). A hierarchy without a general factor. British Journal of Psychology, 8, 271-281. https://doi.org/10.1111/j.2044-8295.1916.tb00133.x

Thorndike, E. L., \& Woodworth, R. S. (1901). The influence of improvement in one mental function upon the efficiency of other functions: III. Functions involving attention, observation and discrimination. Psychological Review, 8, 553-564. https://doi.org/10.1037/h0071363

Thurstone, L. L. (1947). Multiple factor analysis. Chicago, IL: University of Chicago Press. 
Tonidandel, S., \& LeBreton, J. M. (2011). Relative importance analysis: A useful supplement to regression analysis. Journal of Business and Psychology, 26, 1-9.

https://doi.org/10.1007/s10869-010-9204-3

U.S. Bureau of the Census. (1976). Statistical abstract of the United States: 1976 (97th ed.). Washington, DC: Author.

U.S. Department of Labor. (1970). Dictionary of occupational titles (DOT). Washington, DC: Department of Labor.

Uttal, D. H., \& Cohen, C. A. (2012). Spatial thinking and STEM education: When, why, and how? In B. H. Ross (Ed.), Psychology of Learning and Motivation (Volume 57) (pp. 147181). Cambridge, MA: Academic Press. https://doi.org/10.1016/B978-0-12-394293$7.00004-2$

van der Maas, H. L. J., Dolan, C. V., Grasman, R. P. P. P., Wicherts, J. M., Huizenga, H. M., \& Raijmakers, M. E. J. (2006). A dynamical model of general intelligence: The positive manifold of intelligence by mutualism. Psychological Review, 113, 842-861. https://doi.org/10.1037/0033-295X.113.4.842

van der Maas, H. L. J., Kan, K.-J., Marsman, M., \& Stevenson, C. E. (2017). Network models for cognitive development and intelligence. Journal of Intelligence, 5, 16. https://doi.org/10.3390/jintelligence5020016

Van Scotter, J., Motowidlo, S., \& Cross, T. C. (2000). Effects of task performance and contextual performance on systemic rewards. Journal of Applied Psychology, 85, 526-535. https://doi.org/10.1037/0021-9010.85.4.526

Vilorio, D. (2014). STEM 101: Intro to tomorrow's jobs. Occupational Outlook Quarterly, 1(1), 2-12. Retrieved from https://www.bls.gov/careeroutlook/2014/spring/art01.pdf 
Wai, J., Lubinski, D., \& Benbow, C. P. (2009). Spatial ability for STEM domains: Aligning over 50 years of cumulative psychological knowledge solidifies its importance. Journal of Educational Psychology, 101, 817-835. https://doi.org/10.1037/a0016127

Weaver, C. N. (1977). Relationships among pay, race, sex, occupational prestige, supervision, work autonomy, and job satisfaction in a national sample. Personnel Psychology, 30, 437445. https://doi.org/10.1111/j.1744-6570.1977.tb00436.x

Whitely, W., Dougherty, T. W., \& Dreher, G. F. (1991). Relationship of career mentoring and socioeconomic origin to managers' and professionals' early career progress. Academy of Management Journal, 34, 331-350. https://doi.org/10.2307/256445

Wilhelm, O. (2005). Measuring reasoning ability. In O. Wilhelm \& R. W. Engle (Eds.), Handbook of measuring and understanding intelligence (pp. 373-392). Thousand Oaks, CA: Sage.

Wooldridge, J. M. (2007). Inverse probability weighted estimation for general missing data problems. Journal of Econometrics, 141, 1281-1301. https://doi.org/10.1016/j.jeconom.2007.02.002

Zuckerman, M., Kuhlman, D. M., \& Camac, C. (1988). What lies beyond E and N? Factor analyses of scales believed to measure basic dimensions of personality. Journal of Personality and Social Psychology, 54, 96-107. https://doi.org/10.1037/0022-3514.54.1.96 


\section{Footnotes}

${ }^{1}$ As a minimal example, consider a correlation matrix of seven tests that all correlate .30 with each other. The first three tests measure a specific ability and the goal is to estimate the correlation between this specific ability and GMA (composite of all tests). The internal consistencies of the specific ability and GMA are Cronbach's $\alpha=.5625$ and $\alpha=.75$, respectively. The uncorrected correlation between the two composites estimated using the Nunnally et al. formula is .866. Putting these values into the standard Spearman attenuation formula results in the unrealistic corrected correlation of $\rho_{T_{x} T_{y}}=\frac{\rho_{x y}}{\sqrt{\rho_{x x} \rho_{y y y}}}=\frac{.866}{\sqrt{.5625 \times .75}}=1.333$. In contrast, using Zimmerman and Williams' (1977) extended attenuation correction formula yields

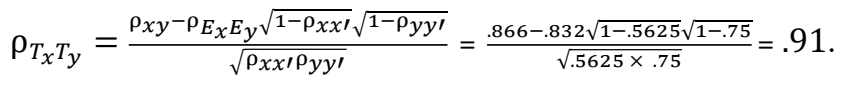


Table 1

Conceptualizations of General Mental Ability and Specific Abilities

\begin{tabular}{|c|c|c|c|}
\hline $\begin{array}{c}\text { Conceptualizatio } \\
\mathrm{n}\end{array}$ & Main publication(s) & Core Idea & $\begin{array}{c}\text { Status of GMA and } \\
\text { specific abilities }\end{array}$ \\
\hline $\begin{array}{l}\text { Two-factor } \\
\text { theory }\end{array}$ & Spearman (1904) & $\begin{array}{l}\text { GMA is a mental energy and causal } \\
\text { entity that is responsible for the positive } \\
\text { manifold (correlations between ability } \\
\text { tests/common factor from a diverse group } \\
\text { of ability tests). Spearman also granted } \\
\text { there was an element of performance on } \\
\text { each cognitive test that was not caused by } \\
g \text { and that this element was specific to } \\
\text { each test (specific abilities). }\end{array}$ & $\begin{array}{l}\text { Causal effect of } \\
\text { GMA on (manifest) } \\
\text { specific abilities }\end{array}$ \\
\hline Bonds model & $\begin{array}{l}\text { Thomson (1916); } \\
\text { Bartholomew et al. } \\
\text { (2009) }\end{array}$ & $\begin{array}{l}\text { Posits that the mind is made up of many } \\
\text { hypothetical units ("bonds") and that } \\
\text { each cognitive task samples a subset of } \\
\text { these bonds, with the correlation between } \\
\text { two tests depending on the degree to } \\
\text { which they share the same bonds. } \\
\text { Individuals may differ in the number of } \\
\text { bonds they possess, explaining individual } \\
\text { differences in what appears to be a } \\
\text { general mental ability. }\end{array}$ & $\begin{array}{l}\text { Bottom-up effect of } \\
\text { specific abilities on } \\
\text { GMA }\end{array}$ \\
\hline $\begin{array}{l}\text { Higher-order } \\
\text { model }\end{array}$ & $\begin{array}{l}\text { Spearman (1939); } \\
\text { Thurstone (1947) }\end{array}$ & $\begin{array}{l}\text { GMA is responsible for the positive } \\
\text { manifold among broad content-aligned } \\
\text { specific ability factors. }\end{array}$ & $\begin{array}{l}\text { Causal effect of } \\
\text { GMA on (latent) } \\
\text { specific abilities }\end{array}$ \\
\hline $\begin{array}{l}\text { Nested- } \\
\text { factors/bi-factor } \\
\text { model }\end{array}$ & $\begin{array}{l}\text { Gustafsson \& Balke } \\
\text { (1993); Holzinger \& } \\
\text { Swineford (1937); } \\
\text { Humphreys (1981) }\end{array}$ & $\begin{array}{l}\text { GMA and specific abilities differ in their } \\
\text { breadth of influence but are not } \\
\text { subordinate to each other, and } \\
\text { independently explain variance in } \\
\text { cognitive tasks. }\end{array}$ & $\begin{array}{l}\text { No causal effect of } \\
\text { GMA on specific } \\
\text { abilities; shared } \\
\text { variance distributed } \\
\text { through } \\
\text { orthogonalization }\end{array}$ \\
\hline $\begin{array}{l}\text { Mutualism } \\
\text { model }\end{array}$ & $\begin{array}{l}\text { van der Maas et al. } \\
(2006 ; 2017)\end{array}$ & $\begin{array}{l}\text { Cognitive processes reciprocally interact } \\
\text { during development and in so doing } \\
\text { positively influence each other, leading to } \\
\text { the emergence of the positive manifold. }\end{array}$ & $\begin{array}{l}\text { Bottom-up effect of } \\
\text { specific abilities on } \\
\text { GMA }\end{array}$ \\
\hline $\begin{array}{l}\text { Hierarchies of } \\
\text { factor solutions }\end{array}$ & $\begin{array}{l}\text { Zuckerman, } \\
\text { Kuhlman \& Camac } \\
\text { (1988); Goldberg } \\
\text { (2006); Lang, } \\
\text { Kersting \& } \\
\text { Beauducel (2016) }\end{array}$ & $\begin{array}{l}\text { The approach correlates factor scores } \\
\text { across different EFA solutions (1-factor, } \\
2 \text {-factor, } 3 \text {-factor, } 4 \text {-factor, etc.), and } \\
\text { is largely a descriptive approach with } \\
\text { no assumptions on causality. }\end{array}$ & $\begin{array}{l}\text { No causal relation } \\
\text { between GMA and } \\
\text { specific abilities; } \\
\text { correlations between } \\
\text { abilities at different } \\
\text { levels of the } \\
\text { hierarchy }\end{array}$ \\
\hline
\end{tabular}


Table 2

Principal-Axis Factor Analyses of the Cognitive Ability Tests in Project TALENT

\begin{tabular}{|c|c|c|c|c|c|c|}
\hline \multirow[b]{2}{*}{ Cognitive ability test } & \multicolumn{5}{|c|}{ 5-Factor oblimin-rotated } & \multirow[b]{2}{*}{ 1-Factor } \\
\hline & 3: Visuospatial & 4: Mathematical & 1: Verbal & $\begin{array}{l}\text { 2: Coding } \\
\text { speed }\end{array}$ & $\begin{array}{l}\text { 5: Short-term } \\
\text { memory }\end{array}$ & \\
\hline Mechanical reasoning & .74 & .09 & .08 & -.04 & -.06 & .62 \\
\hline Visualization $3 \mathrm{~d}$ & .69 & .06 & .02 & .01 & .06 & .62 \\
\hline Visualization $2 \mathrm{~d}$ & .58 & .02 & -.03 & .19 & .06 & .52 \\
\hline Abstract reasoning & .42 & .09 & .25 & .01 & .13 & .72 \\
\hline Intro math & .04 & .89 & -.01 & -.01 & .03 & .78 \\
\hline Advanced math & .07 & .63 & -.01 & .02 & -.09 & .53 \\
\hline Arithmetic computing & -.10 & .42 & .12 & .28 & .20 & .61 \\
\hline Arithmetic reasoning & .17 & .42 & .27 & -.08 & .09 & .77 \\
\hline Reading comprehension & .09 & .05 & .74 & -.08 & .10 & .81 \\
\hline Disguised words & -.02 & .00 & .70 & .22 & .00 & .67 \\
\hline Creativity & .31 & .03 & .49 & -.04 & .04 & .71 \\
\hline Word functions in sentences & -.02 & .32 & .43 & -.01 & .12 & .72 \\
\hline Clerical checking & -.11 & .04 & .08 & .73 & -.05 & .20 \\
\hline Table reading & .05 & .05 & -.02 & .65 & .03 & .28 \\
\hline Object inspection & .26 & -.10 & -.03 & .61 & .08 & .32 \\
\hline Memory for sentences & .04 & -.05 & -.06 & -.01 & .61 & .34 \\
\hline Memory for words & -.07 & .09 & .18 & .00 & .52 & .53 \\
\hline Explained variance (\%) & .13 & .13 & .14 & .09 & .06 & .36 \\
\hline
\end{tabular}


Table 3

Uncorrected and Corrected (Behind the Slash) Intercorrelations, Means, and Standard Deviations of the Study Variables

\begin{tabular}{|c|c|c|c|c|c|c|c|}
\hline Variable & 1 & 2 & 3 & 4 & 5 & 6 & 7 \\
\hline 1. Verbal 1960 & - & & & & & & \\
\hline 2. Mathematical 1960 & $.73 / .89$ & - & & & & & \\
\hline 3. Visuospatial 1960 & $.64 / .77$ & $.60 / .75$ & - & & & & \\
\hline 4. General mental ability $1960^{\mathrm{a}}$ & $.90 / .91$ & $.88 / .89$ & $.85 / .85$ & - & & & \\
\hline 5. Pay $1971-1974$ & $.11 / .12$ & $.20 / .22$ & $.26 / .28$ & $.22 / .22$ & - & & \\
\hline 6. Job prestige $1971-1974$ & $.41 / .45$ & $.40 / .46$ & $.30 / .35$ & $.43 / .46$ & .24 & - & \\
\hline 7. Income 2011-2012 & $.26 / .28$ & $.31 / .34$ & $.25 / .28$ & $.32 / .32$ & .24 & .04 & - \\
\hline$N$ & 363,607 & 363,607 & 363,607 & 363,607 & 84,831 & 15,810 & 1,796 \\
\hline$M$ & $.00^{\mathrm{b}}$ & $.00^{\mathrm{b}}$ & $.00^{\mathrm{b}}$ & .00 & $7,266.71 / 6,760.27$ & $48.49 / 48.46$ & $2.87 / 2.80$ \\
\hline$S D$ & $1.00^{\mathrm{b}}$ & $1.00^{\mathrm{b}}$ & $1.00^{\mathrm{b}}$ & 1.00 & $6,791.15 / 6,632.16$ & $14.39 / 14.46$ & $0.97 / 0.95$ \\
\hline
\end{tabular}

Note. Correlations after the slash were inverse probability weighted when not based on the full sample and corrected for attenuation. $M$ s and $S D$ s after the slash were inverse probability weighted.

${ }^{\mathrm{a}}$ composite based on the verbal, mathematical, and visuospatial tests ${ }^{\mathrm{b}} \mathrm{Z}$-standardized 
Table 4

Incremental Validity Analyses Regressing Pay in 1971-1974, Job Prestige in 1971-1974, and Income in 2011-2012 on General Mental Ability and Three Specific Abilities Measured in 1960

\begin{tabular}{|c|c|c|c|c|c|c|}
\hline \multirow[b]{2}{*}{ Variable } & \multirow[b]{2}{*}{$R^{2}$} & \multirow[b]{2}{*}{$\Delta R^{2}$ vs. Step 1} & \multicolumn{4}{|c|}{$\beta$} \\
\hline & & & General mental & Verbal & Mathematical & Visuospatial \\
\hline \multicolumn{7}{|l|}{ Pay 1971-1974 } \\
\hline Step 1: General mental & $.050[.046 ; .053]$ & - & $.22[.21 ; .23]$ & - & - & 一 \\
\hline Step 2a: Verbal & $.082[.078 ; .087]$ & $.033[.030 ; .036]$ & $.59[.58 ; .61]$ & $-.41[-.43 ;-.39]$ & - & - \\
\hline Step 2b: Mathematical & $.051[.048 ; .055]$ & $.002[.001 ; .002]$ & $.15[.13 ; .17]$ & - & $.08[.07 ; .10]$ & - \\
\hline Step 2c: Visuospatial & $.080[.075 ; .085]$ & $.030[.028 ; .033]$ & $-.05[-.07 ;-.04]$ & - & - & $.32[.31 ; .34]$ \\
\hline Step 2d: All four & $.126[.120 ; .134]$ & $.077[.071 ; .083]$ & $.14[.14 ; .15]$ & $-.50[-.54 ;-.48]$ & $.29[.26 ; .31]$ & $.33[.32 ; .35]$ \\
\hline \multicolumn{7}{|l|}{ Job prestige 1971-1974 } \\
\hline Step 1: General mental & $.208[.195 ; .221]$ & - & $.46[.44 ; .47]$ & - & - & - \\
\hline Step 2a: Verbal & $.217[.204 ; .234]$ & $.009[.006 ; .012]$ & $.26[.22 ; .29]$ & $.22[.18 ; .26]$ & - & - \\
\hline Step 2b: Mathematical & $.224[.211 ; .239]$ & $.016[.012 ; .021]$ & $.24[.21 ; .27]$ & - & $.25[.22 ; .29]$ & - \\
\hline Step 2c: Visuospatial & $.213[.201 ; .227]$ & $.005[.003 ; .008]$ & $.57[.54 ; .60]$ & - & - & $-.14[-.17 ;-11]$ \\
\hline Step 2d: All four & $.229[.216 ; .244]$ & $.021[.016 ; .027]$ & $.28[.26 ; .29]$ & $.11[.05 ; .16]$ & $.20[.15 ; .25]$ & $-.11[-.13 ;-.08]$ \\
\hline \multicolumn{7}{|l|}{ Income 2011-2012 } \\
\hline Step 1: General mental & $.105[.076 ; .135]$ & - & $.32[.27 ; .37]$ & - & - & - \\
\hline Step 2a: Verbal & $.106[.077 ; .137]$ & $.001[.000 ; .006]$ & $.39[.28 ; .49]$ & $-.07[-.18 ; .04]$ & - & - \\
\hline Step 2b: Mathematical & $.116[.084 ; .149]$ & $.012[.003 ; .024]$ & $.12[.02 ; .22]$ & - & $.23[.12 ; .33]$ & - \\
\hline Step 2c: Visuospatial & $.105[.076 ; .137]$ & $.000[.000 ; .004]$ & $.30[.22 ; .38]$ & - & - & $.02[-.06 ; .12]$ \\
\hline Step 2d: All four & $.123[.089 ; .159]$ & $.018[.005 ; .039]$ & $.19[.16 ; .22]$ & $-.18[-.32-.03]$ & $.15[.44 ; .04]$ & $.04[-.04 ; .13]$ \\
\hline
\end{tabular}

Note. The values in parentheses are $95 \%$ confidence intervals estimated using bootstrapping and taking the uncertainty because of the reliability corrections into account. 
Table 5

Relative Importance Analyses Regressing Pay in 1971-1974, Job Prestige in 1971-1974, and Income in 2011 -2012 on General Mental Ability and Five Specific Abilities Measured in 1960

\begin{tabular}{lcrr}
\hline & $\begin{array}{c}\text { Dominance } \\
\text { weight }\end{array}$ & Rank & $R^{2}$ \\
\hline Pay 1971-1974 & $.023[.022 ; .024]$ & $\mathrm{cd}$ & $.126[.120 ; .134]$ \\
$\quad$ General mental & $.030[.028 ; .033]$ & $\mathrm{b}$ & \\
$\quad$ Verbal & $.023[.021 ; .025]$ & $\mathrm{cd}$ & \\
Mathematical & $.050[.047 ; .054]$ & $\mathrm{a}$ & \\
$\quad$ Visuospatial- & & & $.229[.216 ; .244]$ \\
Job prestige 1971-1974 & $.067[.063 ; .071]$ & $\mathrm{ab}$ & \\
$\quad$ General mental & $.062[.057 ; .068]$ & $\mathrm{bc}$ & \\
Verbal & $.068[.062 ; .075]$ & $\mathrm{abc}$ & \\
Mathematical & $.032[.030 ; .035]$ & $\mathrm{d}$ & \\
$\quad$ Visuospatial- & $.034[.025 ; .044]$ & $\mathrm{ab}$ & $123[.089 ; .159]$ \\
Income 2011-2012 & $.022[.017 ; .030]$ & $\mathrm{cd}$ & \\
$\quad$ General mental & $.044[.029 ; .064]$ & $\mathrm{ab}$ & \\
$\quad$ Verbal & $.021[.014 ; .033]$ & $\mathrm{cd}$ & \\
$\quad$ Mathematical & Visuospatial- & & \\
\hline
\end{tabular}

Note. The values in parentheses are $95 \%$ confidence intervals estimated using bootstrapping and taking the uncertainty because of the reliability corrections into account. The ranks are bootstrapped ranks. Ranks with only one letter have a rank order that does not overlap with any other weight (i.e., they substantially differ with a 95\% confidence interval from the other weights). Weights that are labeled with more than one letter do not differ from the weights that are labeled with the same letter (the $95 \%$ confidence intervals of the difference between the respective two weights overlaps). 


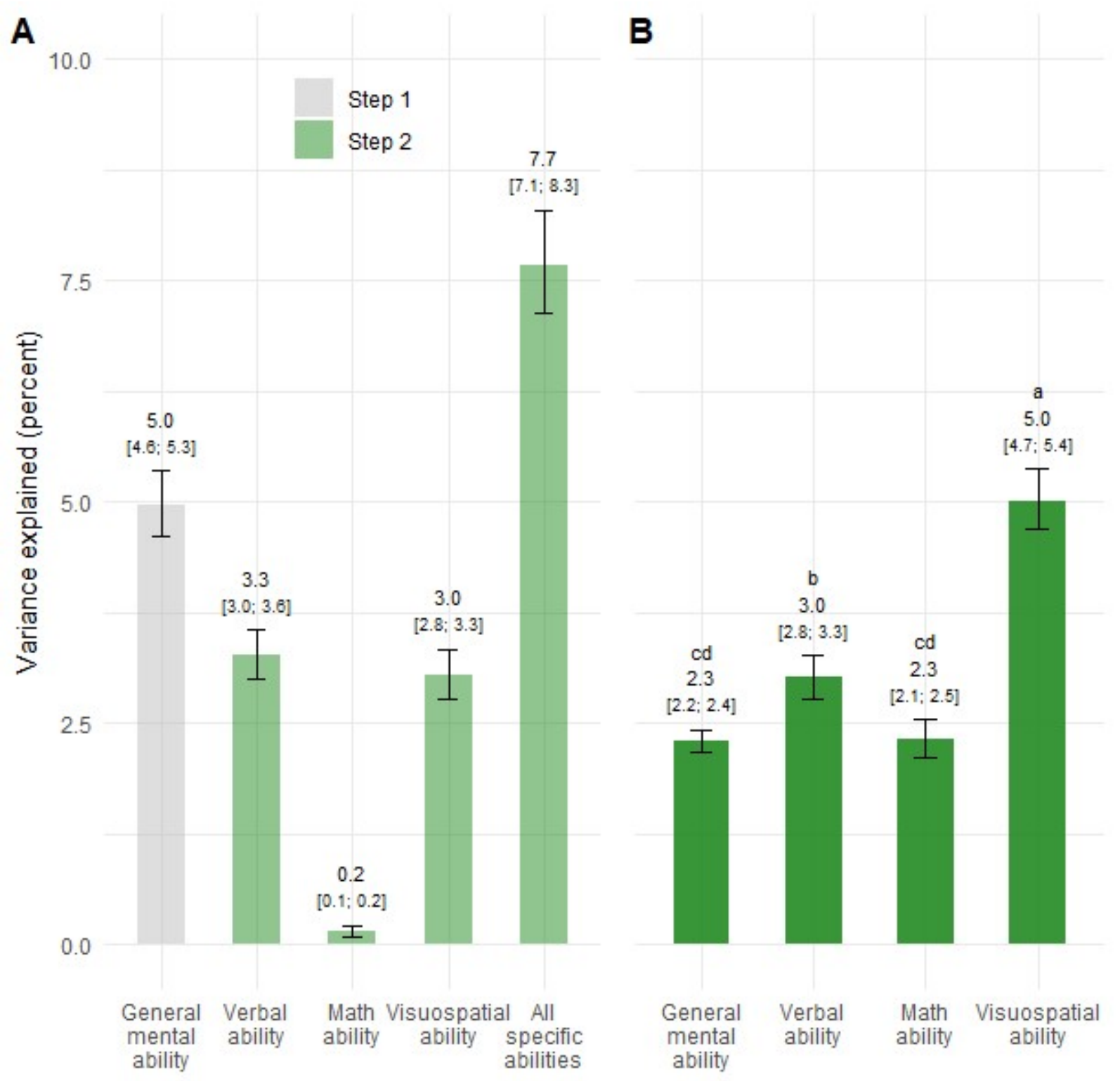

Figure 1. Incremental validity analyses and relative importance analyses regressing pay in 19711974 on GMA and specific abilities measured in 1960. Panel A shows an incremental validity analysis. Panel B shows a relative importance analysis. For each weight, the letter(s) above the bar indicates the bootstrapped rank order. Weights with only one letter have a rank order that does not overlap with any other weight (i.e., they substantially differ with a $95 \%$ confidence interval from the other weights). Weights that are labeled with more than one letter do not differ from the weights that are labeled with the same letter (the $95 \%$ confidence intervals of the difference between the respective two weights overlaps). The values in parentheses are $95 \%$ confidence intervals. 


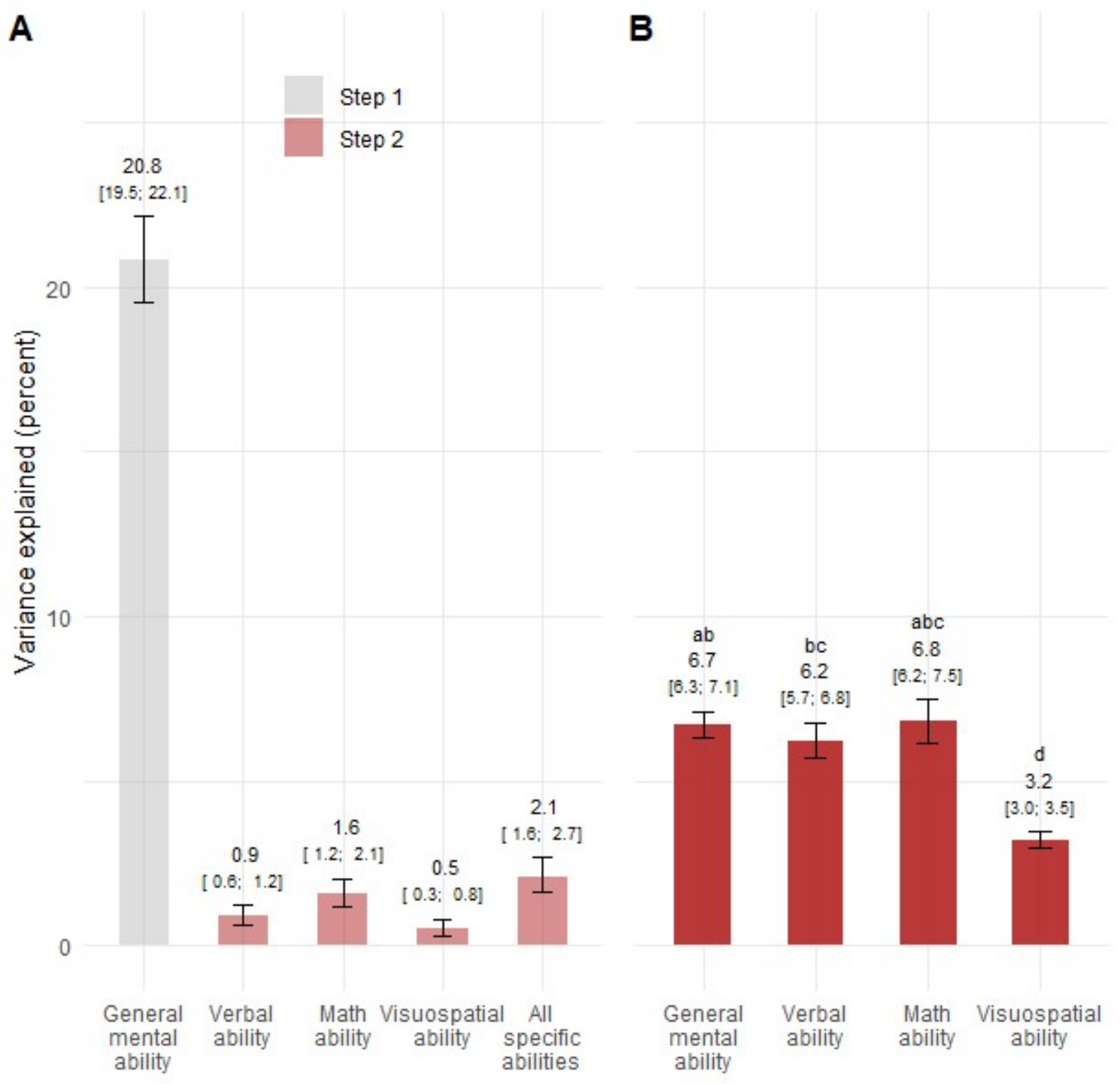

Figure 2. Incremental validity analyses and relative importance analyses regressing job prestige in 1971-1974 on GMA and specific abilities measured in 1960. Panel A shows an incremental validity analysis. Panel B shows a relative importance analysis. For each weight, the letter(s) above the bar indicates the bootstrapped rank order. Weights with only one letter have a rank order that does not overlap with any other weight (i.e., they substantially differ with a $95 \%$ confidence interval from the other weights). Weights that are labeled with more than one letter do not differ from the weights that are labeled with the same letter (the $95 \%$ confidence intervals of the difference between the respective two weights overlaps). The values in parentheses are $95 \%$ confidence intervals. 


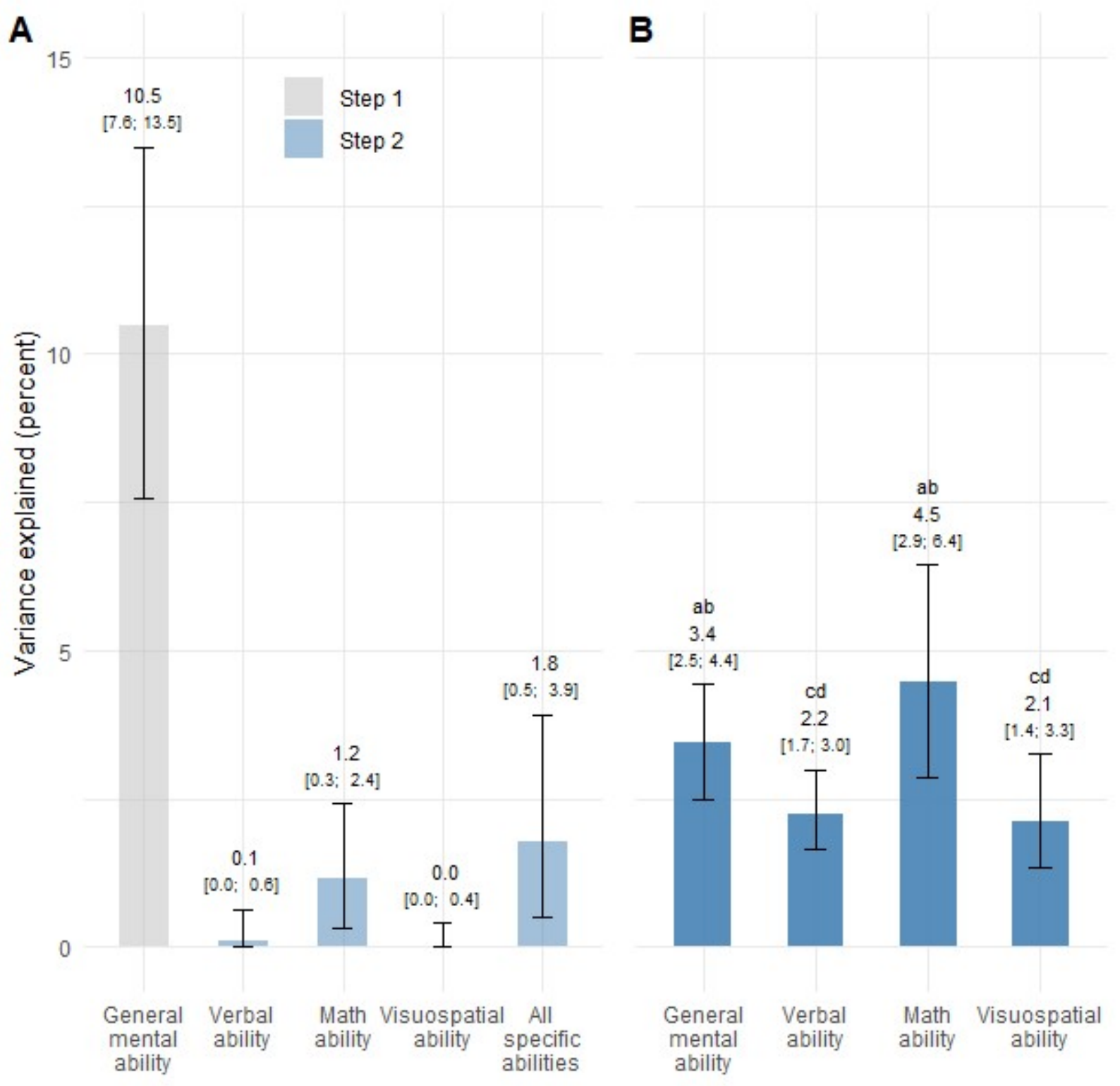

Figure 3. Incremental validity analyses and relative importance analyses regressing income in 2011-2012 on GMA and specific abilities measured in 1960. Panel A shows an incremental validity analysis. Panel B shows a relative importance analysis. For each weight, the letter(s) above the bar indicates the bootstrapped rank order. Weights with only one letter have a rank order that does not overlap with any other weight (i.e., they substantially differ with a 95\% confidence interval from the other weights). Weights that are labeled with more than one letter do not differ from the weights that are labeled with the same letter (the $95 \%$ confidence intervals of the difference between the respective two weights overlaps). The values in parentheses are $95 \%$ confidence intervals. 
Table S1

Uncorrected and Corrected (Behind the Slash) Intercorrelations, Means, and Standard Deviations of the Study Variables

\begin{tabular}{|c|c|c|c|c|c|c|c|c|c|}
\hline Variable & 1 & 2 & 3 & 4 & 5 & 6 & 7 & 8 & 9 \\
\hline 1. Verbal 1960 & - & & & & & & & & \\
\hline 2. Mathematical 1960 & $.73 / .89$ & - & & & & & & & \\
\hline 3. Visuospatial 1960 & $.64 / .77$ & $.60 / .75$ & - & & & & & & \\
\hline 4. Coding speed 1960 & $.27 / .35$ & $.23 / .31$ & $.24 / .32$ & - & & & & & \\
\hline 5. Short-term memory 1960 & $.50 / .75$ & $.44 / .68$ & $.32 / .49$ & $.17 / .28$ & - & & & & \\
\hline 6. General mental ability $1960^{a}$ & $.88 / .91$ & $.85 / .88$ & $.80 / .82$ & $.49 / .48$ & $.60 / .72$ & - & & & \\
\hline 7. Pay 1971-1974 & $.11 / .12$ & $.20 / .22$ & $.26 / .28$ & $.02 / .02$ & $-.03 /-.02$ & $.18 / .19$ & - & & \\
\hline 8. Job prestige 1971-1974 & $.41 / .45$ & $.40 / .46$ & $.30 / .35$ & $.12 / .09$ & $.21 / .30$ & $.41 / .44$ & .24 & - & \\
\hline 9. Income 2011-2012 & $.26 / .28$ & $.31 / .34$ & $.25 / .28$ & $.07 / .07$ & $.12 / .18$ & $.30 / .31$ & .24 & .04 & - \\
\hline$N$ & 363,607 & 363,607 & 363,607 & 363,607 & 363,607 & 363,607 & 84,831 & 15,810 & 1,796 \\
\hline$M$ & $.00^{\mathrm{b}}$ & $.00^{\mathrm{b}}$ & $.00^{\mathrm{b}}$ & $.00^{\mathrm{b}}$ & $.00^{\mathrm{b}}$ & $.00^{\mathrm{b}}$ & $7,266.71 / 6,759.74$ & $48.49 / 48.33$ & $2.87 / 2.80$ \\
\hline$S D$ & $1.00^{\mathrm{b}}$ & $1.00^{\mathrm{b}}$ & $1.00^{\mathrm{b}}$ & $1.00^{\mathrm{b}}$ & $1.00^{\mathrm{b}}$ & $1.00^{\mathrm{b}}$ & $6,791.15 / 6,629.90$ & $14.39 / 14.35$ & $0.97 / 0.95$ \\
\hline
\end{tabular}

Note. Correlations after the slash were inverse probability weighted when not based on the full sample and corrected for attenuation. $M s$ and $S D$ s after the slash were inverse probability weighted.

${ }^{\mathrm{a}}$ composite based on all 17 tests ${ }^{\mathrm{b}} \mathrm{z}$-standardized 
Table S2

Incremental Validity Analyses Regressing Pay in 1971-1974, Job Prestige in 1971-1974, and Income in 2011-2012 on General Mental Ability and Five Specific Abilities Measured in 1960

\begin{tabular}{|c|c|c|c|c|c|c|c|c|}
\hline \multirow[b]{2}{*}{ Variable } & \multirow[b]{2}{*}{$R^{2}$} & \multirow[b]{2}{*}{$D R^{2}$ vs. Step 1} & \multicolumn{6}{|c|}{$\beta$} \\
\hline & & & General mental & Verbal & Mathematical & Visuospatial & Coding speed & STM \\
\hline \multicolumn{9}{|l|}{ Pay 1971-1974 } \\
\hline Step 1: General mental & $.035[.032 ; .038]$ & - & $.19[.18 ; .20]$ & - & - & - & & \\
\hline Step 2a: Verbal & $.046[.043 ; .050]$ & $.011[.009 ; .013]$ & $.40[.38 ; .42]$ & $-.24[-.26 ;-.22]$ & - & - & & \\
\hline Step 2b: Mathematical & $.047[.044 ; .050]$ & $.012[.010 ; .013]$ & $.00[-.02 ; .01]$ & - & $.22[.20 ; .23]$ & - & & \\
\hline Step 2c: Visuospatial & $.085[.081 ; .090]$ & $.050[.047 ; .054]$ & $-.12[-.14 ;-.11]$ & - & - & $.38[.37 ; .40]$ & & \\
\hline Step 2d: Coding speed & $.041[.038 ; .044]$ & $.006[.005 ; .007]$ & $.23[.22 ; .24]$ & & & & $-.09[-.10 ;-.08]$ & \\
\hline $\begin{array}{l}\text { Step 2e: Short-term } \\
\text { Memory (STM) }\end{array}$ & $.079[.074 ; .085]$ & $.044[.040 ; .049]$ & $.39[.37 ; .40]$ & & & & & $\begin{array}{r}-.29[-.30 \\
-.27]\end{array}$ \\
\hline Step 2f: All six & $.143[.137 ; .151]$ & $.108[.102 ; .115]$ & $.14[.13 ; .14]$ & $-.34[-.37 ;-.31]$ & $.32[.30 ; .34]$ & $.30[.29 ; .32]$ & $-.07[-.08 ;-.06]$ & $\begin{array}{r}-.21[-.22 ; \\
-.19]\end{array}$ \\
\hline \multicolumn{9}{|l|}{ Job prestige 1971-1974 } \\
\hline Step 1: General mental & $.193[.180 ; .207]$ & - & $.44[.42 ; .45]$ & - & - & - & & \\
\hline Step 2a: Verbal & $.213[.200 ; .227]$ & $.019[.014 ; .025]$ & $.18[.14 ; .22]$ & $.29[.26 ; .34]$ & - & - & & \\
\hline Step 2b: Mathematical & $.217[.203 ; .232]$ & $.024[.018 ; .031]$ & $.19[.15 ; .22]$ & - & $.29[.26 ; .33]$ & - & & \\
\hline Step 2c: Visuospatial & $.193[.180 ; .207]$ & $.000[.000 ; .001]$ & $43[.41 ; .46]$ & 一 & - & $.01[-.02 ; .04]$ & & \\
\hline Step 2d: Coding speed & $.204[.191 ; .217]$ & $.011[.006 ; .016]$ & $.49[.47 ; .50]$ & & & & $-.11[-.14 ;-.09]$ & \\
\hline Step 2e: STM & $.193[.181 ; .207]$ & $.000[.000 ; .001]$ & $.45[.42 ; .48]$ & & & & & $\begin{array}{r}-.01[-.05 ; \\
.02]\end{array}$ \\
\hline Step 2f: All six & $.230[.217 ; .245]$ & $.037[.029 ; .047]$ & $.27[.26 ; .28]$ & $.18[.12 ; .25]$ & $.21[.16 ; .26]$ & $-.09[-.12 ;-.06]$ & $-.08[-.10 ;-.06]$ & $\begin{array}{r}-.10[-.14 ; \\
-.06]\end{array}$ \\
\hline \multicolumn{9}{|l|}{ Income 2011-2012 } \\
\hline Step 1: General mental & $.095[.067 ; .128]$ & - & $.31[.26 ; .36]$ & - & - & - & & \\
\hline Step 2a: Verbal & $.095[.068 ; .129]$ & $.000[.000 ; .004]$ & $.30[.17 ; .43]$ & $.01[-.12 ; .13]$ & - & - & & \\
\hline Step 2b: Mathematical & $.115[.085 ; .152]$ & $.020[.008 ; .038]$ & $.06[-.05 ; .16]$ & - & $.29[.18 ; .40]$ & - & & \\
\hline Step 2c: Visuospatial & $.098[.069 ; .132]$ & $.003[.000 ; .012]$ & $.23[.15 ; .31]$ & - & - & $.09[.01 ; .18]$ & & \\
\hline Step 2d: Coding speed & $.103[.075 ; .136]$ & $.008[.001 ; .020]$ & $.36[.30 ; .41]$ & & & & $-.10[-.16 ;-.04]$ & \\
\hline Step 2e: STM & $.096[.069 ; .130]$ & $.001[.000 ; .012]$ & $.34[.26 ; .42]$ & & & & & $\begin{array}{r}-.05[-.15 ; \\
.05]\end{array}$ \\
\hline Step 2f: All six & $.126[.095 ; .174]$ & $.031[.016 ; .062]$ & $.19[.15 ; .23]$ & $-.14[-.35 ; .06]$ & $.32[.16 ; .50]$ & $.05[-.05 ; .15]$ & $-.07[-.13 ;-.02]$ & $-.07[-.19 ;$ \\
\hline
\end{tabular}

Note. The values in parentheses are $95 \%$ confidence intervals estimated using bootstrapping and taking the uncertainty because of the reliability corrections into account. 
Table S3

Relative Importance Analyses Regressing Pay in 1971-1974, Job Prestige in 1971-1974, and Income in 2011-2012 on General Mental Ability and Five Specific Abilities Measured in 1960

\begin{tabular}{lrrr}
\hline & Dominance weight & Rank & $R^{2}$ \\
\hline Pay 1971-1974 & $.017[.015 ; .018]$ & $\mathrm{de}$ & $.143[.137 ; .151]$ \\
General mental & $.030[.028 ; .033]$ & $\mathrm{b}$ & \\
Verbal & $.053[.050 ; .056]$ & $\mathrm{a}$ & \\
Mathematical & $.003[.002 ; .004]$ & $\mathrm{f}$ & \\
Visuospatial- & $.023[.020 ; .026]$ & $\mathrm{c}$ & \\
Coding speed & $.018[.017 ; .019]$ & $\mathrm{de}$ & \\
Short-term memory & & & $.230[.217 ; .245]$ \\
Job prestige 1971-1974 & $.060[.054 ; .066]$ & $\mathrm{abc}$ & \\
General mental & $.063[.056 ; .070]$ & $\mathrm{ab}$ & \\
Verbal & $.028[.025 ; .030]$ & $\mathrm{d}$ & \\
Mathematical & $.004[.003 ; .005]$ & $\mathrm{f}$ & \\
Visuospatial- & $.021[.019 ; .023]$ & $\mathrm{e}$ & \\
Coding speed & $.055[.052 ; .059]$ & $\mathrm{bc}$ & \\
Short-term memory & & & $.126[.095 ; .174]$ \\
Income 2011-2012 & $.019[.015 ; .027]$ & $\mathrm{cd}$ & \\
General mental & $.046[.029 ; .069]$ & $\mathrm{a}$ & \\
Verbal & $.021[.013 ; .033]$ & $\mathrm{bcd}$ & \\
Mathematical & $.004[.002 ; .009]$ & $\mathrm{f}$ & \\
Visuospatial- & $.008[.006 ; .016]$ & $\mathrm{e}$ & \\
Coding speed & $.028[.020 ; .038]$ & $\mathrm{bc}$ & \\
Short-term memory &
\end{tabular}

Note. The values in parentheses are $95 \%$ confidence intervals estimated using bootstrapping and taking the uncertainty because of the reliability corrections into account. The ranks are bootstrapped ranks. Ranks with only one letter have a rank order that does not overlap with any other weight (i.e., they substantially differ with a $95 \%$ confidence interval from the other weights). Weights that are labeled with more than one letter do not differ from the weights that are labeled with the same letter (the $95 \%$ confidence intervals of the difference between the respective two weights overlaps). 